\title{
A COMPARATIVE ASSESSMENT OF THE L1 AND L2 READING PERFORMANCE OF GRADE 7 LEARNERS IN ENGLISH AND XITSONGA
}

TV Manyike \& EM Lemmer

University of South Africa

The role of English and the indigenous languages in South African schooling is highly contested. Research endorses the mother tongue (L1) as the most appropriate language of learning and teaching (LoLT) and the basis for the addition of a second language (L2). However, in South Africa English is the preferred LoLT and English proficiency is integral to academic achievement. This article reports on an investigation of Grade 7 Xitsonga-speaking learners' reading performance in English and in Xitsonga. Based on a study of the literature on the link between language proficiency and academic success, an empirical inquiry assessed the reading performance of grade 7 Xitsonga-speaking learners using a standardised test in English and in Xitsonga. Learners' reading performance in both Xitsonga, their L1, and English, their LoLT since grade 4, was poor.

Keywords: standardised test performance; reading skills; English Second Language; primary language; underachievement

\section{INTRODUCTION}

In South Africa, English has become the language of economic, technological and political discourse. In practice this provides a strong motivation for parents and learners to value English proficiency, to choose English as the language of learning and teaching (LoLT) from the outset of schooling, or to choose an early and sudden introduction to English as LoLT (Heugh, 2000:6). However, extensive international and national research has found that without sufficient support for the development of first language (L1) proficiency in the school and at home, non-English learners plunged too quickly into mainly English or English only education are likely to fail academically (Cummins, 1984; Macdonald, 1990; Baker \& Garcia, 1996; Heugh, 2000; 2002; 2005; 2008; Baker, 2006). The development of L1 proficiency and the successful subsequent addition of English (or, for that matter, any language) are interrelated. Poor development of L1 has a detrimental effect on the second language (L2) and vice versa, a phenomenon termed subtractive bilingualism by Cummins (1984). An early and most significant study in this regard was carried out in South Africa by Macdonald (1990), who showed that learners who switch medium of instruction before they have sufficiently developed the new target language of learning do not succeed and eventually, both L1 and L2 are negatively affected. Moreover, the past history of racial segregation in South Africa led to ethnically differentiated residential areas, the rural-urban differences in the prevalence of the 
use of English and poor language teaching conditions in schools (Heugh, Diedericks, Prinsloo \& Herbst, 2007). These factors have contributed to the lack of exposure to English among learners whose mother tongue is not English and they do not develop adequate English proficiency for academic use (Lazenby, 1997:30; Mahlobo, 1999:44). In South Africa it has been estimated that a large percentage of the school-going population experiences barriers to learning related to lack of language proficiency (Booyse, 1995:52). Heugh (2002:42) argues that the overall poor matriculation results since 1994 are due to the language barrier faced by about $80 \%$ of candidates who are speakers of African languages.

A study of similar nature to the one described in this article was conducted by Jordaan and Suzman (2002), who investigated learners' competencies in L1 (IsiZulu) and L2 (English). Findings indicated that selected township schools in Soweto had greater success with bilingual learning programmes than similar schools in rural KwaZulu Natal. The study recommended that the academic level of the schools should be improved to increase learners' proficiency levels in both English and IsiZulu. A similar study was conducted by Waner (2002) regarding learners' competencies in L1 (IsiZulu) and L2 (English). The findings confirm learners' lack of proficiency in both L1 and L2. The tests used in the investigation described in this article differ from those used by Jordaan and Suzman (2002) and Waner (2002). The latter studies used concepts from the Revised National Curriculum Statement for Grade 7; this investigation used standardised tests compiled under the auspices of the Human Sciences Research Council (HSRC).

Against this background, the article reports on part of the investigation done for a doctoral thesis (Manyike, 2007). The broad research aim was to compare English (L2) and L1 (in this case, Xitsonga) reading and writing performance of selected primary school learners who are not English L1 speakers at selected schools in Gauteng. This aim was addressed by means of a literature study and an empirical investigation using a standardised language performance test. This article is limited to the findings regarding reading performance in English and in Xitsonga as obtained in the empirical investigation.

\section{THE RELATIONSHIP BETWEEN L1 AND L2 PROFICIENCY}

L2 acquisition does not take place in isolation from L1 development. L1 and L2 proficiency interact with one another and L2 development benefits and builds on what children know and learn in the first language. According to the 'interdependence hypothesis' (Cummins, 1992:233; Cummins, 2001:71), language skills learned in L1 can be transferred to L2 and the more developed the L1, the more readily competence develops in L2. For example, a child learning to read in a second language would not have to relearn the full range of skills presupposed in initial literacy acquisition and the second process is expected to be relatively more economical (Macdonald, 1993). Furthermore, learners who do not have a developed proficiency in L1 and whose L1 language maintenance is not supported tend to lose proficiency in the former as they acquire a L2, a condition known as 'subtractive bilingualism'. Conversely, learners who are fluent in the L1 and whose language is respected and its maintenance supported acquire an L2 while retaining their L1. This is known as 'additive bilingualism' (Baker, 2006). Certainly the aim of effective schools should be to provide L2 learners with an 'additive' model of education. The disadvantages of 'subtractive' bilingual language programmes have been extensively documented (Macdonald, 1993; Baker, 2006). As Heugh (1995) points out, plunging learners into English 'immersion' programmes 
where their L1 is neither recognised nor used and expecting learners to become competent users of English as LoLT in three to four years is unrealistic and irresponsible. Unfortunately for many African children, including South African learners, insufficient time is given to L1 development and instruction before the switch to English as LoLT is made, and before sufficient competency in either L1 or L2 has been acquired (Heugh, 2005:1; Jordaan \& Suzman, 2002:53; Waner, 2002). Thus, effective education eludes many of these children who experience a decline in L1 development together with insufficient acquisition of L2 to ensure their academic success.

Many learners worldwide who are learning through a L2 have been found to run a greater risk of underachievement (Ovando, 2000: 1). In this regard, the use of language in informal everyday situations is distinguished from language used in most academic situations. This distinction is known as 'basic interpersonal communicative skills' (BICS) and 'cognitive academic language proficiency' (CALP) (Cummins, 2000a:55). According to Cummins (2000a: 60), learners require both 'BICS' and 'CALP' to achieve optimally in the school situation. Where there is a language deficit in 'CALP', learners lack the language proficiency to master academic content and to become proficient in school discourse. This lack is often hidden on the playground or in everyday conversation because the learners have already acquired informal, colloquial language or 'BICS'. According to Cummins (2000a:56), the latter consist of the 'visible' aspects of language such as pronunciation, basic vocabulary and grammar which allow learners to converse fluently in undemanding everyday situations. The more sophisticated command of language or 'CALP' is necessary (Cummins, 2000a:56) to use a language to grasp concepts; establish relationships between concepts or information sets; analyse, synthesise, classify, store and retrieve information; and articulate information processed in oral and written form (Cummins, 1992:231). L2 learners using English as LoLT can demonstrate higher order thinking in their L1; however, they may lack the 'CALP' required to carry out higher cognitive operations through the medium of English (Wales, 1990:51) and may thus experience difficulty with abstract academic concepts and terminology which are less easily understood and experienced than ideas and terms used in social interaction. This may not even apply to many learners in South Africa whose L1 is not well developed due to language deprivation (Macdonald, 1993). Teachers may not realise that this cognitive difficulty is due to language and may ascribe it to a lack of intellectual ability (Chamot, 1999:109). Chamot (1999:110) has further linked Bloom's taxonomy of educational objectives to the BICS/CALP distinction. The language skills of pronunciation and vocabulary (BICS) are sufficient for the surface level of cognitive processing identified by Bloom: recall; comprehension; and application. However, the deeper levels of cognitive processing as identified by Bloom are linked to CALP. These deeper levels comprise: analysis; synthesis; and evaluation.

Another useful distinction has been made between 'context-embedded' and 'context-reduced' communication. In 'context-embedded' communication learners can actively negotiate meaning and language is supported by a wide range of paralinguistic or situational cues, such as body language. This comprises a cognitively undemanding situation where a person has mastery of language skills sufficient to enable easy communication. On the other hand during 'context-reduced' communication there are very few cues to convey meaning. The communication relies primarily on linguistic cues to meaning and may even involve suspending knowledge of the real world in order to manipulate the logic of the message. This comprises a cognitively demanding situation where information must be processed quickly without accompanying situational clues (Baker, 2006:153). Classroom communication is 
largely characterised by cognitively demanding tasks. Where English is used as LoLT, L2 learners often find it difficult to grasp the terminology and concepts presented. Notwithstanding, Ramani, Kekana, Modiba and Joseph (2007:207) indicate that L2 can be effectively employed alongside L1 to assist learners to engage with cognitive demanding tasks for grasping new concepts in the absence of specialist terms available in L2.

Thus, authentic language proficiency requires proficiency in both 'BICS' and 'CALP' while attention must be given to the kind of contextual support and the degree of cognitive involvement acquired by learning tasks. Furthermore, the determination of a learner's proficiency levels in 'BICS' and 'CALP' is no straightforward matter. Tests assessing language proficiency based on BICS might show learners to be quite fluent, however, tests which require cognitive operations to be carried out show that this surface fluency is not equally reflected in 'CALP' (Cummins, 2000a:56). Moreover, tests assessing intelligence, aptitude and interest may not render accurate results as learners not proficient in the language of the test are often unable to complete many of the tasks correctly (Fradd \& Weismantel, 1989:78). Academic problems might be attributed to underlying learning difficulties rather than to the lack of the appropriate language skills. For instance, after three years in an English medium school language minority learners in the United States still measured 15 IQ points below the norm for the grade (Fradd \& Weismantel, 1989:80).

\section{RESEARCH DESIGN}

Based on the literature study outlined above, part of the empirical investigation (Manyike, 2007) focused on grade 7 Xitsonga-speaking learners' reading performance in English and in Xitsonga in three selected primary schools in Tshwane.

\section{The sample}

The sample comprised 162 grade 7 learners from three primary schools situated in two townships in the Tshwane metropolitan area. Two classes of grade 7 learners were tested in School 1 and one grade 7 class in each of the other two schools (Schools 2 and 3) respectively. The schools were chosen on the basis of the LoLT used in the first three years of schooling. Xitsonga is the LoLT from grade $\mathrm{R}$ to grade 3; after which learners switch to English, which is also offered as a school subject. All participants were L1 Xitsonga speakers. Thus, in grade 7 learners are using English as LoLT and require English proficiency skills to cope with the curriculum. Learners in grade 7 were chosen because the seventh year of schooling represents an important stage in the development of CALP (Cummins, 2000b; Jordaan \& Suzman, 2002). Five to seven years is generally considered necessary to develop CALP in the L2 and by the time learners reach grade 7, they should have had sufficient exposure to both the academic content of the curriculum and to English as LoLT. Grade 7 is also the final year of primary school before the learner progresses to secondary school where the demands and complexity of the curriculum increase, and there is greater use of decontextualised forms of language and less opportunity to foster language learning. Therefore, grade 7 learners must have the required CALP in their LoLT because it is critical for further academic achievement in secondary school. 


\section{Data gathering and data analysis}

Data were gathered by means of the Reading Performance Test in English (Intermediate Level) as developed by the Human Sciences Research Council (HSRC). This is a standardised test aimed at determining the testee's reading comprehension in the Intermediate Phase (Chamberlin \& Reinecke, 1992). The test is applicable to L1 as well as L2 speakers, although different norms apply for these groups. This test was also translated into Xitsonga by a Xitsonga language expert in the Department of Linguistics at University of South Africa to assess the learners' reading performance in Xitsonga, and is referred to as the Reading Performance Test in Xitsonga (Intermediate level). The Reading Performance Test (Chamberlin \& Reinecke, 1992) has two components: comprehension and grammar. To carry out the test, a candidate is supplied with a test booklet, an answer sheet a pencil and an eraser. The contents and structure of the test are summarised in Table 1 and Table 2.

The test manual does not indicate what is considered a pass mark as performance depends on the context in which the test is written. However, $40 \%$ (or a raw score of 16 out of a possible total of 40 of the combined scores for comprehension and grammar) is recommended as a guideline for both the English and the Xitsonga Reading Performance Test and was used in this inquiry.

Table 1: Component: reading comprehension

\begin{tabular}{|l|c|l|}
\hline Skill being tested denotative & Number of items & Question numbers \\
\hline $\begin{array}{l}\text { Recognising of } \\
\text { meaning of words }\end{array}$ & 1 & 26 \\
\hline $\begin{array}{l}\text { Understanding details of } \\
\text { content }\end{array}$ & 9 & $1 ; 3 ; 4 ; 5 ; 6 ; 8 ; 10 ; 15 ; 31$ \\
\hline $\begin{array}{l}\text { Making general inferences } \\
\text { based on the given text }\end{array}$ & 1 & 17 \\
\hline $\begin{array}{l}\text { Making inferences related to } \\
\text { the writer's intention }\end{array}$ & 2 & $12 ; 14$ \\
\hline $\begin{array}{l}\text { Making inferences related to } \\
\text { the main idea }\end{array}$ & 3 & $27 ; 28 ; 29$ \\
\hline $\begin{array}{l}\text { Selecting precise words to } \\
\text { describe something in context }\end{array}$ & & \\
\hline
\end{tabular}

(Chamberlain \& Reinecke, 1992:17)

Table 2: Component: Grammar

\begin{tabular}{|l|c|l|}
\hline Skills being tested & Number of items & Question numbers \\
\hline $\begin{array}{l}\text { Recognising correct idiomatic } \\
\text { use }\end{array}$ & 5 & $16 ; 18 ; 19 ; 20 ; 30$ \\
\hline $\begin{array}{l}\text { Selecting correct use of parts } \\
\text { of speech }\end{array}$ & 9 & $32-40$ \\
\hline $\begin{array}{l}\text { Making inferences related to } \\
\text { the atmosphere }\end{array}$ & 1 & 13 \\
\hline $\begin{array}{l}\text { Recognising expanded } \\
\text { meaning of summarised text }\end{array}$ & 2 & $23 ; 25$ \\
\hline $\begin{array}{l}\text { Selecting appropriate language } \\
\text { for the situation }\end{array}$ & 1 & 24 \\
\hline
\end{tabular}


In order to reduce the effect that prior testing in English could have had on the results of the same test taken in Xitsonga, a cross-over research design was employed: learners in School 1 and School 2 wrote the Reading Performance Text in English and then the Reading Performance Test in Xitsonga, and learners in School 3 wrote the Reading Performance Test in Xitsonga and the Reading Performance Test in English thereafter. A lapse of one month was allowed between the completion of the test in each language, which was considered sufficient time to avoid the learning effect (Macmillan \& Schumacher, 1993: 65). The total number of participants who wrote each test differed slightly due to absenteeism on the day the respective test was taken. The tests were scored by the researcher; an expert statistician used an SSPS statistical package to obtain descriptive statistics from the raw data.

\section{FINDINGS}

\section{The reading performance test in English}

A total of 162 learners wrote the Reading Performance Test in English. The results are presented according to the scores for the comprehension component (Q1-12, 14; 15; 17; 21; 22; $26-29 ; 31$ ) and for the grammar component (Q 13; 16; 18-20; 23-25; 32-40). The comprehension component had a maximum possible score of 22 and the grammar component had a maximum possible score of 18. The histogram in Figure 1 gives the tabulated results of the English comprehension component.

\section{Figure 1: English comprehension}

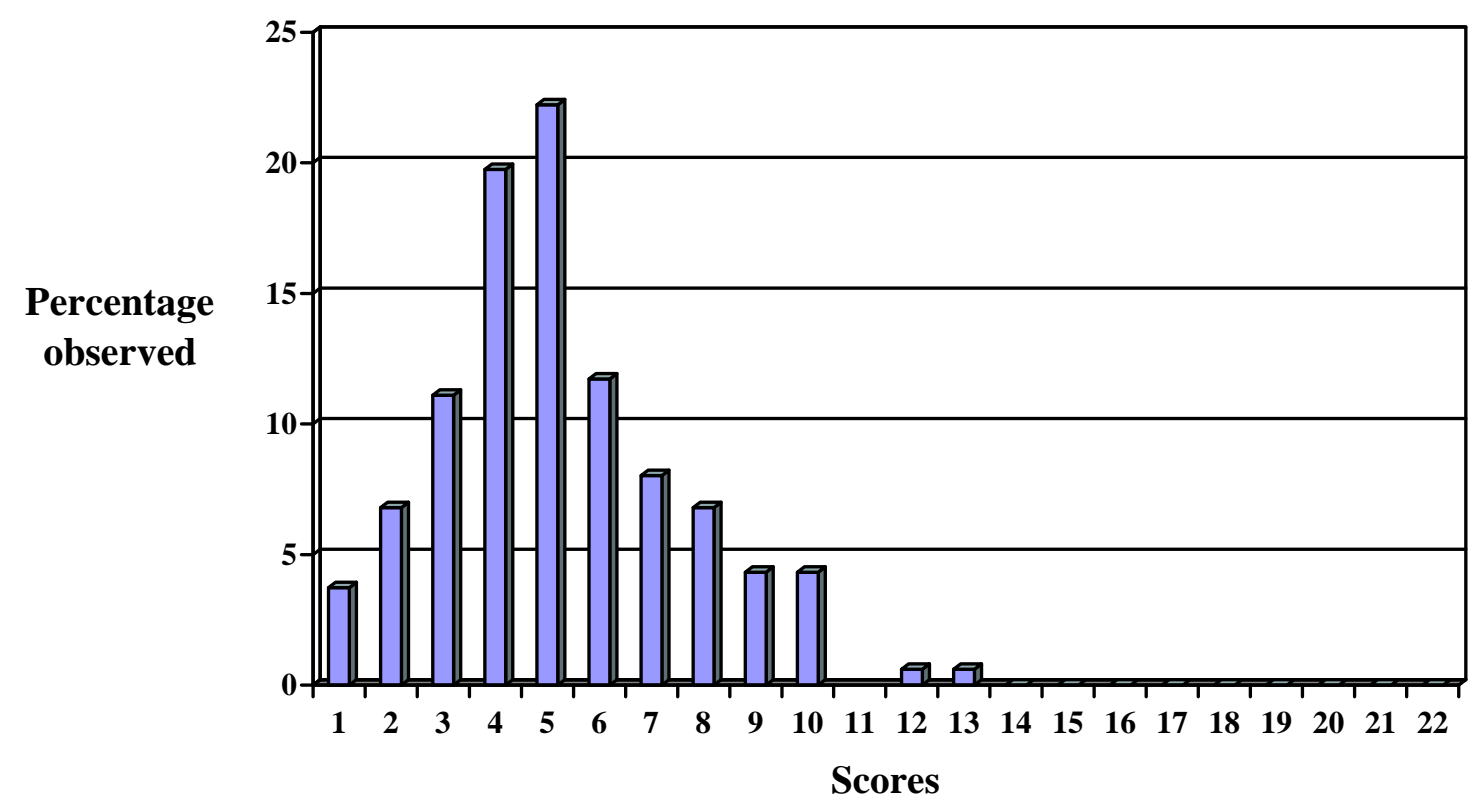


Figure 1 shows that the possible scores ranged from one to 22 . Just over ninety per cent $(90.12 \%)$ of the learners scored below the $40 \%$ pass mark (which is equivalent to 9 out of maximum possible score of 22) and $10 \%$ of the learners passed. Only $1.22 \%$ of the learners obtained a score of at least $11(50 \%)$. The largest group of scores $(41.97 \%)$ ranged from a score of 4 to 5 which indicates very poor performance. Overall, the mean score was 5.15, with a standard deviation of 2.31 .

The histogram in Figure 2 gives the results of English grammar component.

\section{Figure 2: English grammar}

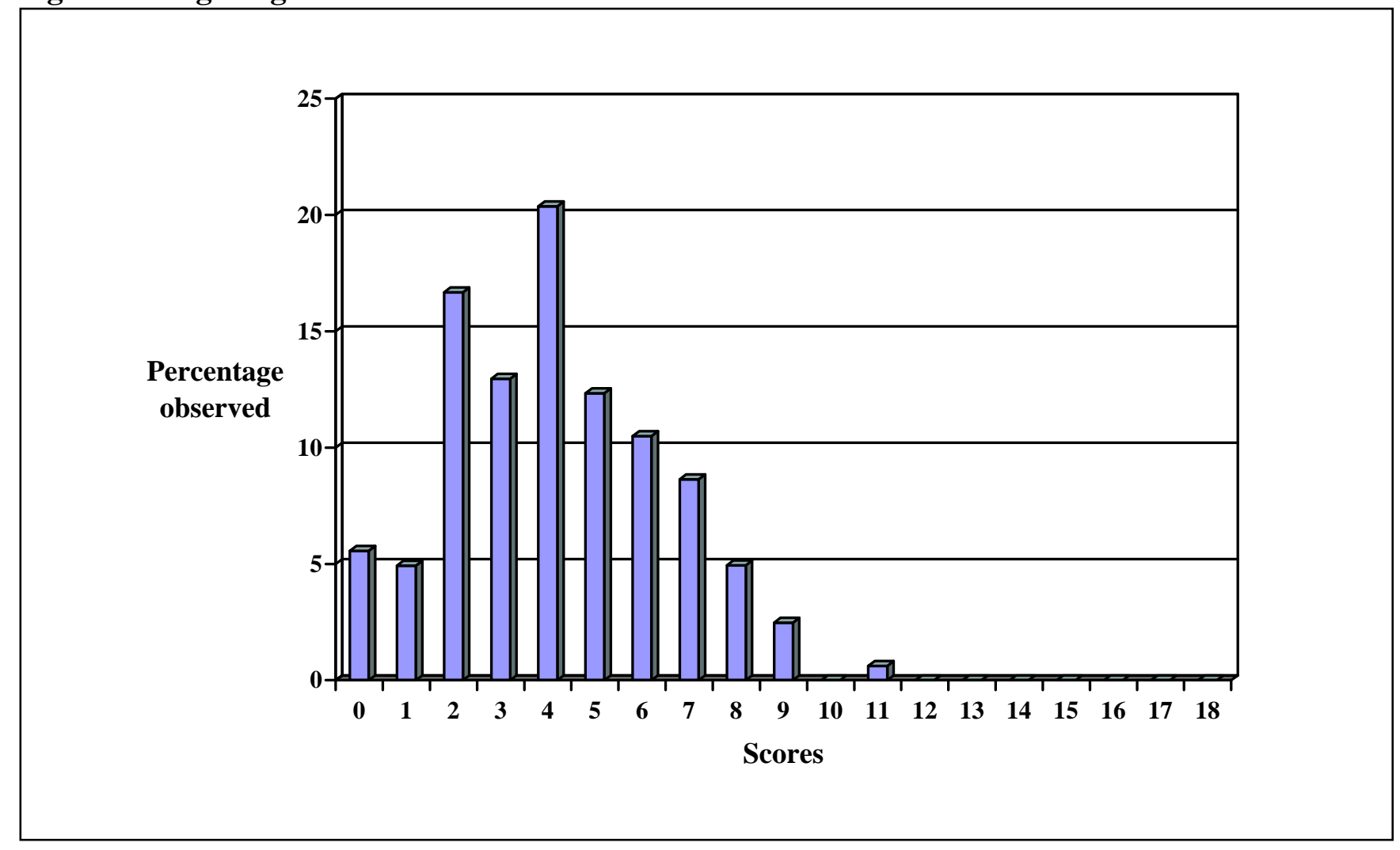

Figure 2 shows that the possible scores ranged from zero to 18. Just over eighty three per cent $(83.33 \%)$ of the learners scored below the $40 \%$ pass mark (which is equivalent to 7 out of maximum possible score of 18) and $17 \%$ of the learners passed. Only $3.09 \%$ of the learners obtained a score of $9(50 \%)$. The majority of the scores (i.e., 81.47\%) ranged from 2 to 7 scores which indicates poor performance. An additional $5.56 \%$ of learners obtained a zero score. The mean score was 4.13 , with a standard deviation of 2.31 .

\section{The reading performance test in Xitsonga}

A total of 153 learners out of possible 162 learners (due to absenteeism on the test day) wrote the Reading Performance Test in Xitsonga. The results are presented according to the scores in the comprehension component $(\mathrm{Q} 1-12,14 ; 15 ; 17 ; 21 ; 22 ; 26-29 ; 31)$ and the grammar component (Q $13 ; 16 ; 18 ; 19 ; 20 ; 23-25 ; 32-40)$. The comprehension had a maximum possible score of 22 and the grammar had a maximum possible score of 18. 
Figure 3, which depicts performance in the comprehension component in Xitsonga, shows that the possible scores ranged from zero to 22. Just over eighty-six per cent $(86.29 \%)$ of the learners scored below the $40 \%$ pass mark (which is equivalent to 9 out of maximum possible score of 22) and $14 \%$ of the learners passed. Only six per cent $(5.87 \%)$ of the learners obtained 50\%. The largest group of scores (i.e., 72.55\%) ranged between a score of 3 and 7; and $0.66 \%$ of the learners obtained a zero score, which indicates very poor performance. Overall, the mean score was 5.79, with a standard deviation of 2.75 .

\section{Figure 3: Xitsonga comprehension}

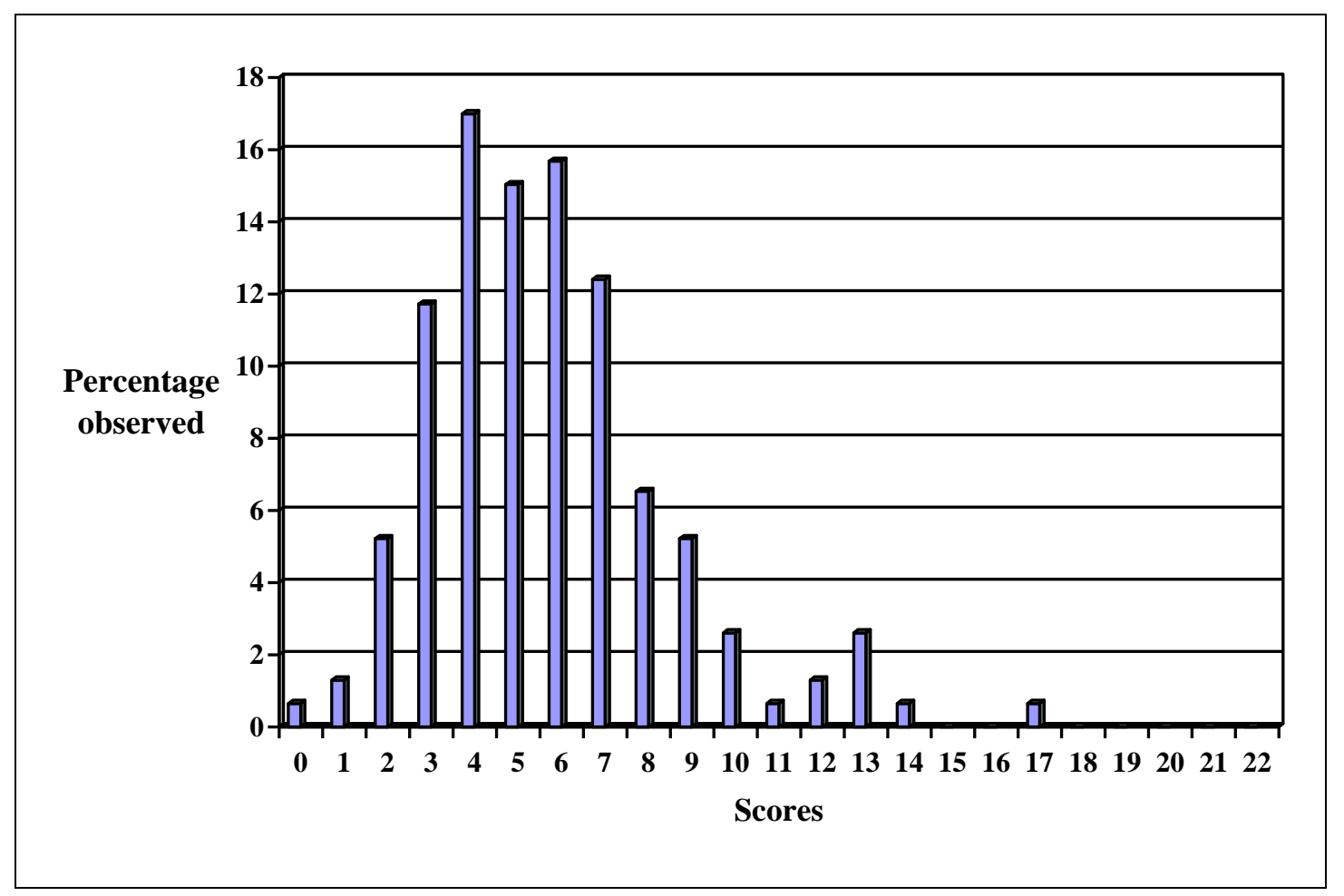

The histogram in Figure 4 gives the results of the grammar component in Xitsonga. Possible scores ranged from zero to 18 . About sixty-eight per cent $(67.72 \%)$ of the learners scored below the $40 \%$ pass mark (which is equivalent to 7 out of maximum possible score of 18), and $32 \%$ of the learners passed. Only about five per cent $(5.22 \%)$ of the learners obtained a mark of at least $50 \%$. However, $0.65 \%$ obtained a score of $100 \%$. The largest group of the scores (i.e., $33.33 \%$ ) ranged from a score of 3 to 4 ; and $9.15 \%$ of learners obtained a zero score, which indicates very poor performance. Overall, the mean score was 5.14 , with a standard deviation of 3.24 .

The scores for the learners' performance in the respective tests (English and Xitsonga) were combined so learners' overall reading performance in English and Xitsonga could be shown. In other words, the scores obtained for comprehension (Figures 1 and 3) and for grammar (Figures 2 and 4) were combined for the respective tests. The histogram in Figure 5 gives the comparison of the combined results of the Reading Performance Test in English and Xitsonga. 
The mean score for reading performance in English was 9.31 (standard deviation $=3.2$ ). The highest score obtained for performance in English was 19 with no learner obtaining zero. The mean score for the Xitsonga comprehension component was 10.84 (standard deviation = 4.78). The highest score obtained for the Xitsonga comprehension component was 31 and one learner obtained the lowest score of zero.

Figure 4: Xitsonga grammar

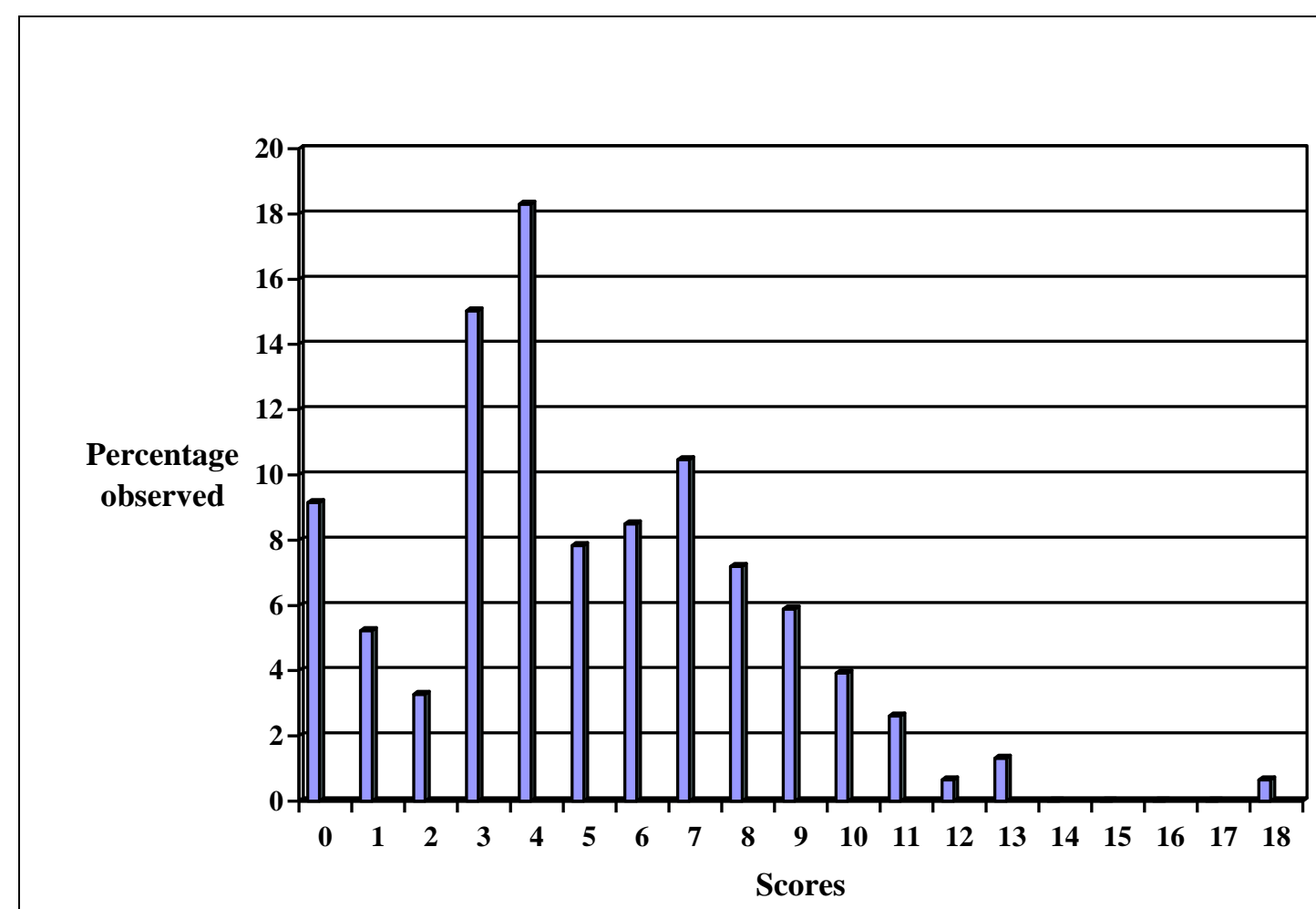

\section{A comparison of results in the reading performance test in English and the reading performance test in Xitsonga}

Overall, learners performed better in English than in Xitsonga at lower scores up to the score of 12. In contrast, at scores higher than 12, learners performed better in Xitsonga than in English. This indicates that these learners were able to perform better in their L1. However, none of the learners obtained English scores greater than 19; and only a little over three per cent $(3.26 \%)$ scored more than 19 out of 40 in Xitsonga. Forty per cent (40\%) pass level statistical information is provided under each figure above. An independent t-test sample statistical procedure was used to compare the English and the Xitsonga reading performance. There were no statistical differences between the learners' English and Xitsonga reading performance overall $(\mathrm{p}>0.05)$.

The mean score for reading performance in English was 9.31 (standard deviation $=3.2$ ). The highest score obtained for performance in English was 19 with no learner obtaining zero. The mean score for the Xitsonga comprehension component was 10.84 (standard deviation = 4.78). The highest score obtained for the Xitsonga comprehension component was 31 and one learner obtained the lowest score of zero. 
Overall, learners performed better in English than in Xitsonga at lower scores up to the score of 12. In contrast, at scores higher than 12, learners performed better in Xitsonga than in English. This indicates that these learners were able to perform better in their L1. However, none of the learners obtained English scores greater than 19; and only a little over three per cent $(3.26 \%)$ scored more than 19 out of 40 in Xitsonga. Forty per cent (40\%) pass level statistical information is provided under each figure above. An independent t-test sample statistical procedure was used to compare the English and the Xitsonga reading performance. There were no statistical differences between the learners' English and Xitsonga reading performance overall $(\mathrm{p}>0.05)$.

Figure 5: Comparison of results of the Reading Performance Tests in English and Xitsonga

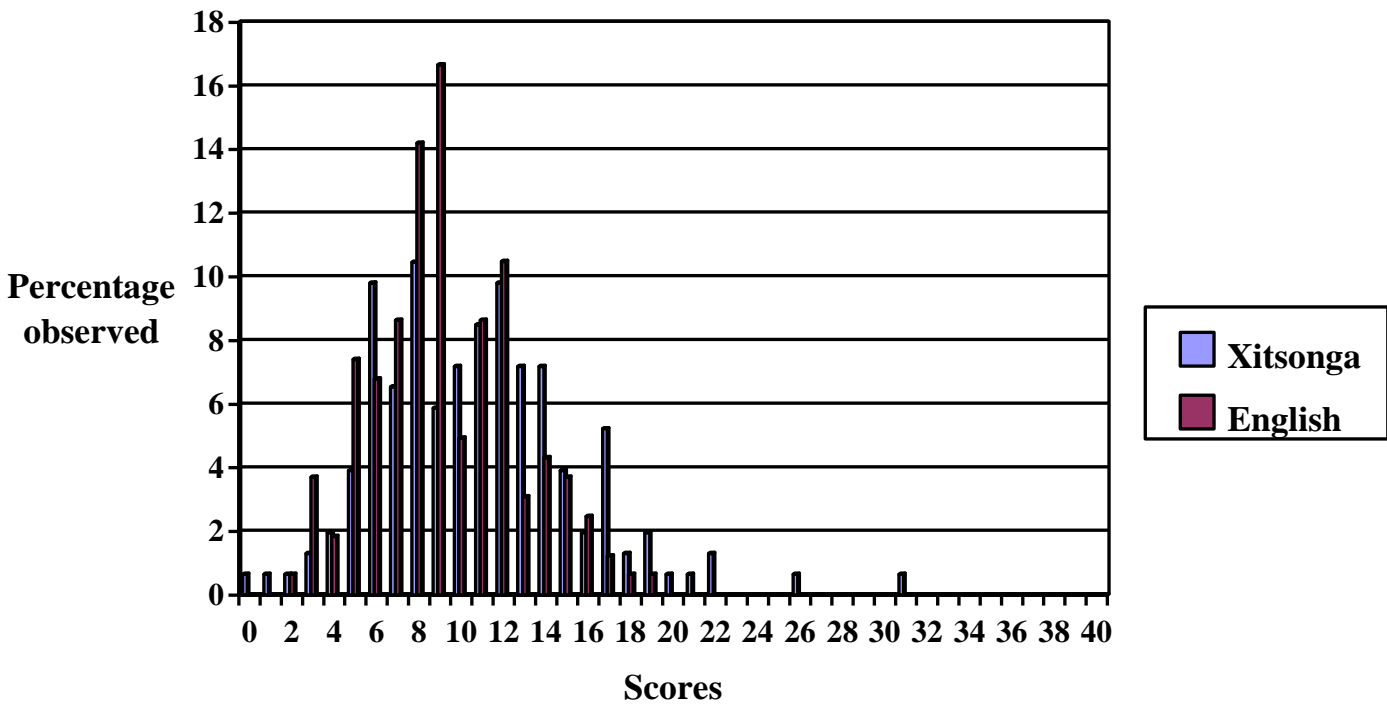

\section{DISCUSSION AND CONCLUSIONS}

Both the English and Xitsonga Proficiency Reading Tests were assessed out of the possible maximum score of 40 . The discussion interrogates the results based on the two components of the test (comprehension and grammar) for both languages.

As was seen above, learners performed very poorly in the reading comprehension in both languages. The results for English and Xitsonga reading comprehension show that these learners obtained a mean of 5.15 (standard deviation $=2.31$ ) and 5.79 (standard deviation $=$ 2.75) out of the possible maximum score of 22 for the respective tests. The observed mean of 5.15 for English comprehension was less than $25 \%$ of the possible score, which is far below the normal mean score of 12. The same was true for Xitsonga comprehension. However, in cases of incorrect answers for the comprehension component in both languages, the Xitsonga responses showed greater clarity of expression. Those learners who performed well in Xitsonga did not necessarily perform well in English; however, those who performed well in 
English also did well in Xitsonga. There appears to be no statistically significant differences between the learners' achievement in the English and the Xitsonga reading comprehension. Some learners, however, obtained a far better score for Xitsonga comprehension (e.g., 17 out of 22); however, others obtained a zero score. It is judged that since these were Xitsonga L1 speakers, no learner should have obtained as low as a zero score.

The results for English and Xitsonga grammar show a similar pattern to the reading comprehension results: learners obtained a mean of 4.13 (standard deviation $=2.31$ ) and 5.14 (standard deviation $=3.24$ ) out of the possible maximum score of 22 for the respective tests. The highest score obtained for English grammar was 11 out of 22; while the highest score obtained for Xitsonga grammar was 18 out of 22. However, the lowest score in both languages was zero, with $5.56 \%$ of the learners obtaining a zero score in English grammar and $9.15 \%$ obtaining a zero score for Xitsonga grammar.

Various researchers (Malherbe, 1977; Ianco-Worrall, 1972; Macdonald, 1990; DACST, 1996) have debated bilingualism in schooling and its relationship to academic achievement in the South African context. Most recently, Heugh $(2000 ; 2002 ; 2005 ; 2008)$ has argued that models in which children receive mother tongue instruction (L1) in African settings for up to only three years (Grade 1-3) before the switch to English are flawed. This is due to the following: language education models used in African settings have their origins in L2 programmes designed in Europe to teach children a second language to be used for conversational skills and not as the LoLT; these models do not accommodate the cognitive needs of children who must use L2 across the curriculum as the LoLT; and they do not consider the disadvantaged, multilingual home settings of these children nor the poorly resourced language learning milieu in schools (Heugh 2005:14). As mentioned earlier in this article, five to seven years is generally considered necessary to establish the necessary level of proficiency in the L2 and prevent the development of subtractive bilingualism (Baker, 2006). Therefore, an injudicious switch in LoLT from L1 to L2 before at least five years of schooling places learners at serious risk of educational failure. Reflecting on the findings on South African learners whose performance was tracked from the time they made an early switch to English as LoLT at the beginning of grade 4, Heugh (2005:3) concludes that significant academic gaps become evident early on; such learners are likely to achieve between only $30 \%$ to $40 \%$ in L2 by grade 12 . In how far are the results of the investigation discussed in this article consistent with these research findings? The participants had switched from L1 (Xitsonga) to L2 (English) in Grade 4, that is, only after three years of schooling. In keeping with the prediction made by Heugh (2005), by grade 7 their reading comprehension in almost all cases was significantly below what was required in both languages and their performance in their L1 was only marginally better than in their L2 in the grammar component. Their overall reading performance in their LoLT is below the required level and their bilingualism is subtractive.

\section{REFERENCES}

BAKER, C. 2006. Foundations of bilingual education and bilingualism. $4^{\text {th }}$ edition. Clevedon: Multilingual Matters.

BAKER, C \& O GARCIA. 1996. Foundations of bilingual education and bilingualism. Clevedon: Philadelphia Press. 
BOOYSE, AM. 1995. The milieu of deprived family. In Kapp, JA (Ed.), Children with problems: An anthropological perspective. Pretoria: Van Schaik.45-60.

CHAMBERLAIN, JC \& S REINECKE. 1992. Manual: Proficiency Test English second language intermediate level. Pretoria: Human Sciences Research Council.

CHAMOT, A. 1999. Cognitive Academic Language Learning Approach (CALLA): Theoretical framework and instructional applications. In Chamot, UA (Ed.), Linguistics, language acquisition, and language variation: Current trends and future prospects. Georgetown: Georgetown University Press.103-158.

CUMMINS, J. 1984. Heritage language education: Fact and fiction. Orbi, 15:3-6.

. 1992. Language proficiency, bilingualism, and academic achievement. In RichardAmato, PA \& MA Snow (Eds), The multicultural classroom. New York: Longman.91-104.

2000a. Language, power and pedagogy: Bilingual children in the crossfire. Clevedon: Multilingual Matters.

. 2000b. Putting language proficiency in its place: Responding to critiques of the conversational/academic language distinction. In Cenoz, J \& U Jessner (Eds), English in Europe: The acquisition of a third language. Clevedon: Multilingual Matters.54-83.

. 2001. Instructional conditions for trilingual development. International Journal of Bilingual Education and Bilingualism, 4(1):61-75.

DACST. 1996. Towards a national language plan for South Africa: A final report of the Language Task Group (LANGTAG). Pretoria: Department of Arts, Culture Science and Technology.

DEPARTMENT OF EDUCATION (DoE). 2002. The Revised National Curriculum Statement. Pretoria: Government Printers.

FRADD, SH \& C WEISMANTEL (Eds), 1989. Meeting the needs of culturally and linguistically different learners: A handbook for educators. Boston: College-Hill.

HEUGH, K 1995. The multilingual school: modified dual medium. In Heugh, K, A Siegruhn \& P Plüddeman (Eds), Multilingual education for South Africa. Isando: Heinemann.83-88.

. 2000. The case against bilingual and mulitilingual education in South Africa. Occasional Paper no. 6. Cape Town: PRAESA.

. 2002. The case against bilingual and mulitilingual education in South Africa. Perspectives in Education, 20(1):59-77.

. 2005. Mother tongue education is best. HSRC Review, 3(3):1-3.

2008. Language policy and education in Southern Africa. In May, W \& NH Hornberger (Eds), Encyclopaedia of language and education. Volume 1:355-367. New York: Stronger.

HEUGH, K, GAM DIEDERICKS, CH PRINSLOO \& DL HERBST. 2007. Assessment of the language and mathematics skills of grade 8 learners in the Western Cape. www.hsrc.ac.za/Research_Publication-6705. [15 February 2008].

JORDAAN HS, \& S SUZMAN. 2002. Investigation of the possible effects of English Education on home language competence. University of Witwatersrand: Johannesburg. 
IANCO-WORRALL, AD. 1972. Bilingualism and cognitive development, 43:1390-1400.

LAZENBY, SB. 1997. An examination of learner's preferences in self-access study in language centres: Planning for the millennium. Plymouth: Circles Press.

MACDONALD, CA. 1993. Towards a new primary curriculum in South Africa. Pretoria: HSRC.

1990. Crossing the threshold into standard three in black education: The consolidated main report of the Threshold Project. Pretoria: Human Sciences Research Council.

MACMILLAN, JH \& S SCHUMACHER. 1993. Research in education: A conceptual introduction. $3^{\text {rd }}$ edition. London: Harper \& Collins.

MAHLOBO, EB. 1999. Factors related to the underachievement of junior secondary school pupils. Unpublished doctoral thesis, University of South Africa.

MALHERBE, EG. 1977. The bilingual school: A study of bilingualism in South Africa. Johannesburg: Central News Agency.

MANYIKE, TV. 2007. The acquisition of academic English language proficiency among grade 7 learners in South African schools. Unpublished doctoral thesis, University of South Africa.

OVANDO, CJ. 2000. Editor's Preface. In Ovando, CJ \& P McClaren (Eds), The politics of multiculturalism and bilingual education. Boston: McGraw-Hill. 34- 36.

RAMANI, E, T KEKANA, M MODIBA \& M JOSEPH. 2007. Terminology development versus concept development through discourse: Insights from a dual-medium BA degree. South African Linguistics and Applied Language Studies, 25 (2):207-223.

WALES, L. 1990. Literacy for learners of English as a second language. In Christie, F (Ed), Literacy for a changing world. Sydney: Acer.167 -186.

WANER, N. 2002. Understanding the key words in the grade 7 curriculum by ESL Learners in English and their home language. Unpublished master's dissertation, University of the Witwatersrand, Johannesburg.

\section{BIOGRAPHIC NOTE}

Tintswalo Vivian Manyike is a senior lecturer in the Department of Educational Studies at the University of South Africa, Her research interests include multicultural/ bilingual education, teaching English as a second language and language policy in education. (Email: manyitv@unisa.ac.za).

Eleanor Lemmer is Professor of Comparative Education in the Department of Further Teacher Education at the University of South Africa. Her research interests include language policy in multicultural schools in South Africa and parent involvement. (Email: lemmeem@unisa.ac.za). 